\title{
Taxation and the Taylor Principle
}

\author{
Rochelle M. Edge and Jeremy B. Rudd \\ Division of Research and Statistics \\ Federal Reserve Board *
}

October 31, 2002

\begin{abstract}
We add a nominal tax system to a sticky-price monetary business cycle model. When nominal interest income is taxed, the coefficient on inflation in a Taylor-type monetary policy rule must be significantly larger than one in order for the model economy to have a determinate rational expectations equilibrium. When depreciation is treated as a charge against taxable income, an even larger weight on inflation is required in the Taylor rule in order to obtain a determinate and stable equilibrium. These results have obvious implications for assessing the historical conduct of monetary policy.
\end{abstract}

${ }^{*}$ Corresponding author: Rochelle M. Edge, Mail Stop 61, Federal Reserve Board, 20th and C Streets NW, Washington DC 20551. Email: rochelle.m.edge@frb.gov. We thank Ben Bernanke, Lars Svensson, Andrea Tambalotti, Michael Woodford, and especially Darrel Cohen and Alan Viard for useful comments and conversations; all errors are ours. The views expressed in this paper are our own and do not necessarily reflect the views of the Board of Governors or the staff of the Federal Reserve System. 
The intellectual tradition in monetary analysis has caused the effects of the economy's fiscal structure to be ignored ... [T]he fiscal structure of our economy is a key determinant of the macroeconomic equilibrium and therefore of the effect of monetary policy. - Feldstein (1982, pp. 160-61)

\section{Introduction}

One of the more durable conclusions to have emerged from the modern literature on optimal monetary policy is that the central bank must raise real interest rates in response to higher rates of inflation. In the context of the feedback rules that are typically used in this literature to model and evaluate monetary policy, this prescription - which is often labeled the Taylor principle - militates placing a weight of at least unity on the inflation term in an interestrate rule. ${ }^{1}$ In formal terms, models in which this principle fails to hold are unable to deliver determinate rational-expectations equilibria; hence, the Taylor principle is interpreted as providing a minimum requirement that monetary policy must meet if it is to have a stabilizing influence on the economy.

In general, the monetary business cycle models that have been used to derive the Taylor principle have, of necessity, taken a fairly simple form. Simple models, of course, have a distinct advantage in that they can usually be solved cleanly (often analytically), thus permitting a straightforward interpretation of their results. One potential problem, however, is that an overly simplified model might fail to capture a key dimension of reality, thereby limiting its practical relevance. As a result, an important avenue for research involves assessing the conduct of monetary policy in the context of more richly specified models.

This paper demonstrates that a simple but realistic extension to an otherwise standard monetary business cycle model can significantly alter the restrictions that must be placed on an interest-rate feedback rule in order to ensure equilibrium determinacy. Specifically, we assume the existence of a fiscal system in which households' nominal income is subject to taxation, and where depreciation of capital is considered a charge against taxable income. When household income - in particular, interest income - is taxed, a rise in the nominal interest rate does not yield a one-for-one increase in the posttax real interest rate (the interest rate that is relevant for the determination of aggregate demand). As a result, in order to ensure determinacy, the inflation coefficient in a Taylor rule must be significantly

\footnotetext{
${ }^{1}$ More precisely, the Taylor principle requires the coefficient on inflation to exceed unity if the central bank sets interest rates without reference to the output gap; the condition is relaxed slightly if the output gap receives a positive weight in the interest-rate feedback rule.
} 
greater than unity, by an amount that depends positively on the tax rate and negatively on the central bank's inflation target.

When depreciation allowances are incorporated into the model, the results are modified in an interesting way. The discounted present value of depreciation allowances enters the user cost of capital. However, because the tax system measures depreciation in historicalcost terms, the relevant present value is computed using the nominal posttax interest rate. Hence, the existence of depreciation allowances implies that nominal interest rates will have an independent influence on aggregate demand. This provision of the tax code therefore yields an alternative channel through which the fiscal system can affect equilibrium determinacy; moreover, it turns out that the presence of depreciation allowances can also affect equilibrium stability. Thus, in general, an even larger weight on inflation in the Taylor rule is required in order to obtain a determinate and stable rational expectations equilibrium, where the size of this additional increase depends on the weight given to the output gap in the policy rule, and on the sensitivity of depreciation allowances (and, therefore, the user cost) to changes in nominal interest rates.

These findings are worth highlighting for at least two reasons. First, the result that nominal taxation can alter the form of the Taylor principle in a manner that is qualitatively and quantitatively significant illustrates an interesting intersection between monetary and fiscal policy that is absent from standard analyses of optimal monetary policy. Second, our findings suggest that evaluations of the historical conduct of monetary policy should take into account changes in the government's tax structure. In particular, the benchmark against which an estimated Taylor rule must be compared need not be fixed over time.

The remainder of the paper is organized as follows. Section 2 presents the optimizing model that underpins our analysis, and derives the conditions that must be imposed on the central bank's policy rule in order to yield a determinate rational expectations equilibrium. Section 3 adds a nominal tax system to the model, and discusses how the conditions for determinacy are affected by this extension. We then develop a variant of the baseline model in which there is a well-defined capital investment decision. This extended model is used in section 5 to assess the effect of nominal depreciation allowances on capital income, which provide an alternative channel through which the tax system can influence equilibrium determinacy. Finally, section 6 concludes. 


\section{A Simple Optimizing Model}

The baseline model that we consider is an optimizing sticky-price monetary business cycle model. Models of this type have been used to analyze policy rules and equilibrium determinacy by a number of authors, including Clarida, Galí, and Gertler (1999, 2000) and Woodford (2000). Although this framework is by now relatively familiar, in what follows we discuss its derivation in some detail, as this will later permit us to highlight what modifications are required in order to bring taxation into the analysis.

The economy is characterized by the following set of agents: a continuum of identical households distributed over the unit interval, each of which consumes the economy's output and supplies the economy's homogeneous labor input; a continuum of monopolistically competitive intermediate-goods producers, each of which hires labor inputs to produce its output; a final-good producer, which uses the differentiated intermediate goods to produce output for final demand; and a monetary authority who closes the model by setting nominal interest rates according to a Taylor rule with interest rate smoothing. Initially, we assume no role for government.

\subsection{The Household's Problem}

The preferences of household $i$ (where $i \in[0,1]$ ) are represented by the utility function

$$
U_{0}=E_{0}\left\{\sum_{t=0}^{\infty} \delta^{t}\left[\ln C_{t}^{i}+\frac{1}{1+s}\left(H_{t}^{i}\right)^{1+s}\right]\right\},
$$

where $C_{t}^{i}$ is defined as household $i$ 's consumption, $H_{t}^{i}$ is its labor supply, and $\delta$ and $s$ denote the household's discount factor and labor supply elasticity, respectively. ${ }^{2}$ The household's budget constraint is given by

$$
E_{t}\left[A_{t+1}^{i} / R_{t}\right]=A_{t}^{i}+W_{t} H_{t}^{i}+\operatorname{Profits}_{t}^{i}-P_{t} C_{t}^{i}
$$

where $A_{t}^{i}$ is the nominal value of household $i$ 's bond holdings at the beginning of period $t$, $W_{t}$ represents the nominal wage paid on labor, $P_{t}$ denotes the price of final output (the consumption good), and $R_{t}$ is the gross nominal interest rate between periods $t$ and $t+1$.

\footnotetext{
${ }^{2}$ By assuming log utility, we have implicitly set the intertemporal elasticity of substitution for consumption equal to one. This is done in order to yield an IS curve that is identical to what Clarida, Galí, and Gertler (2000) employ in their work.
} 
The household, taking as given the expected path of the gross nominal interest rate $R_{t}$, the price level $P_{t}$, the wage rate $W_{t}$, profits income, and the initial bond stock $A_{0}^{i}$, solves

$$
\max _{\left\{C_{t}^{i}, H_{t}^{i}\right\}_{t=0}^{\infty}} E_{0}\left\{\sum_{t=0}^{\infty} \delta^{t}\left[\ln C_{t}^{i}+\frac{1}{1+s}\left(H_{t}^{i}\right)^{1+s}\right]\right\} \text { subject to equation (2). }
$$

This utility-maximization problem yields the usual Euler equation for household consumption, together with a supply curve for labor:

$$
\frac{1}{C_{t} P_{t}}=\delta E_{t}\left[\frac{R_{t}}{C_{t+1} P_{t+1}}\right] \text { and } \frac{W_{t}}{P_{t}}=\left(H_{t}\right)^{s} C_{t}
$$

(Note that we have omitted the $i$ superscripts in equation (4) because all households are identical in this framework.)

\subsection{Intermediate-Goods Producers}

The monopolistically competitive firm $j$ takes as given the nominal wage rate $W_{t}$ and hires labor to produce a differentiated good $Y_{t}^{j}$ according to the production function $Y_{t}^{j}=H_{t}^{j}-$ $F C$. Here $H_{t}^{j}$ is firm $j$ 's labor input, and $F C$ is a fixed cost (set equal to $F C=\frac{Y_{*}}{\theta-1}$ ) that is assumed in order to preclude positive steady-state profits. The production function implies a labor demand schedule of the form $H_{t}^{j}=Y_{t}^{j}+F C$, and also implies that nominal marginal $\operatorname{cost} M C_{t}^{j}$ is equal to the economy-wide wage rate (that is, $M C_{t}^{j}=W_{t}$ ).

Firms are Calvo price-setters: In any period a fraction $(1-\eta)$ of firms can reset their price, while the remaining fraction $\eta$ are constrained to charge their existing price (which is indexed to the steady-state inflation rate). In this setup, a firm that is able to reset its price in period $t$ takes as given its nominal marginal cost $M C_{t}^{j}$, the aggregate price level $P_{t}$, and aggregate output $Y_{t}$, and solves:

$$
\max _{\left\{P_{t}^{j}\right\}} \sum_{k=0}^{\infty} \eta^{k} E_{t}\left[Q_{0, k}\left(\left(P_{t}^{j}-M C_{t+k}^{j}\right) Y_{t+k}^{j}-P_{t} F C\right)\right] \text { s.t. } Y_{t+k}^{j}=Y_{t+k}\left(\frac{P_{t}^{j}}{P_{t+k}}\right)^{-\theta}
$$

where $Q_{t, t+v}$ is the nominal stochastic discount factor (which firms also take as given). ${ }^{3}$ This profit-maximization problem implies that the optimal reset price is given by

$$
P_{t}^{j}=\frac{\sum_{k=0}^{\infty} \eta^{k} E_{t}\left[Q_{0, t} M C_{t+k}^{j} \theta Y_{t+k}\right]}{\sum_{k=0}^{\infty} \eta^{k} E_{t}\left[Q_{0, t}(\theta-1) Y_{t+k}\right]} .
$$

\footnotetext{
${ }^{3}$ If we denote the marginal utility of consumption as $M U_{t}$, then the nominal stochastic discount factor $Q_{t, t+v}$ equals $\frac{\delta^{v} M U_{t+v} / P_{t+v}}{M U_{t} / P_{t}}$.
} 


\section{$2.3 \quad$ Final-Good Producers}

The representative final-good producing firm takes as given the prices $\left\{P_{t}^{j}\right\}_{j=0}^{1}$ that are set by each intermediate-good producer, and chooses intermediate inputs $\left\{Y_{t}^{j}\right\}_{j=0}^{1}$ to minimize its cost of producing aggregate output $Y_{t}$ subject to a Dixit-Stiglitz production function. Specifically, the firm solves:

$$
\min _{\left\{Y_{t}^{j}\right\}_{t=0}^{\infty}} \int_{0}^{1} P_{t}^{j} Y_{t}^{j} d j \text { s.t. } Y_{t} \leq\left(\int_{0}^{1} Y_{t}^{j \frac{\theta-1}{\theta}} d j\right)^{\frac{\theta}{\theta-1}} .
$$

This cost-minimization problem yields demand functions for each intermediate good that are given by $Y_{t}^{j}=Y_{t}\left(P_{t}^{j} / P_{t}\right)^{-\theta}$ where $P_{t}$, the price of final output, is defined as $P_{t}=$ $\left(\int_{0}^{1}\left(P_{t}^{j}\right)^{1-\theta} d z\right)^{\frac{1}{1-\theta}}$.

\subsection{The Monetary Authority}

The central bank sets the nominal interest rate according to a Taylor-style feedback rule. Specifically, the target nominal interest rate $\bar{R}_{t}$ responds to deviations of output and the (gross) inflation rate from their respective target levels $\bar{\Pi}$ and $\bar{Y}$ :

$$
\bar{R}_{t}=\left(E_{t} \Pi_{t+1} / \bar{\Pi}\right)^{\beta}\left(Y_{t} / \bar{Y}\right)^{\gamma} R_{*},
$$

where $R_{*}$ denotes the economy's steady-state (equilibrium) interest rate. For simplicity, we will assume that the central bank targets the economy's steady-state level of output, implying that $\bar{Y}=Y_{*}$. Policymakers smoothly adjust the actual interest rate to its target level:

$$
R_{t}=\left(R_{t-1}\right)^{\rho}\left(\bar{R}_{t}\right)^{1-\rho} \exp \left[\xi_{t}^{r}\right]
$$

where $\xi_{t}^{r}$ represents a policy shock. ${ }^{4}$

\subsection{Equilibrium}

Equilibrium is an allocation $\left\{Y_{t}, C_{t}, H_{t},\left\{H_{t}^{j}\right\}_{j=0}^{1}\right\}_{t=0}^{\infty}$ and a sequence of values $\left\{\Pi_{t}, W_{t} / P_{t}\right.$, $\left.\left\{M C_{t}^{j} / P_{t}\right\}_{j=0}^{1}, R_{t}\right\}_{t=0}^{\infty}$ that satisfy the following conditions: (i) the household solves (3);

\footnotetext{
${ }^{4}$ We have assumed a forward-looking Taylor rule (i.e., a rule in which the central bank targets $E_{t} \Pi_{t+1}$ ) in order to simplify the later interpretation of our results. It is straightforward to demonstrate that none of our substantive conclusions are changed by instead assuming a Taylor rule where the central bank responds to deviations of $\Pi_{t}$ from its target. In particular, the lower bound required for a determinate equilibrium is the same if we assume that the central bank targets $\Pi_{t}$ instead of $E_{t} \Pi_{t+1}-c$.f. Woodford (2000, p. 29).
} 
(ii) the final-good producing firm solves (7); (iii) all intermediate-good producing firms minimize costs and meet the demand for their output at their posted price, resetting that price (when able) so as to maximize (5); (iv) the monetary authority follows (8) and (9); (v) the goods market clears (which with identical households implies that $C_{t}=Y_{t}$ ); and, (vi) the labor market clears (implying that $H_{t}=\int_{0}^{1} H_{t}^{j} d i$ ). Agents are assumed to take $R_{-1}$ and the sequence of interest rate shocks $\left\{\xi_{t}^{r}\right\}_{t=0}^{\infty}$ as given. In the absence of any monetary policy shocks, the symmetric steady-state equilibrium of the model is characterized by $Y_{*}=C_{*}=\left(\frac{\theta-1}{\theta}\right) H_{*}, H_{*}=H_{*}^{j}=1, \Pi_{*}=\bar{\Pi}$ (where $\bar{\Pi}$ is the inflation target set by the central bank), $\frac{W_{*}}{P_{*}}=\frac{M C_{*}^{j}}{P_{*}}=\left(\frac{\theta-1}{\theta}\right)$, and $R_{*}=\frac{\bar{\Pi}}{\delta}$.

\subsection{The Log-Linearized Model}

We log-linearize the model about its steady-state in order to examine the conditions for a determinate rational expectations equilibrium. The model's aggregate supply relation is obtained from equation (6), and is given by

$$
\pi_{t}=\delta E_{t} \pi_{t+1}+\frac{(1-\eta)(1-\eta \delta)}{\eta} \cdot m c_{t}
$$

where $\pi_{t}$ is the log-deviation of inflation from its steady-state level, and $m c_{t}$ is the logdeviation of real marginal cost (which is identical across firms) from its steady-state level.

A few simple steps allow us to replace $m c_{t}$ in equation (10) with the output gap. First, the intermediate-good producing firm's cost-minimization problem implies that $m c_{t}=w_{t}$, (where $w_{t}$ is the log-deviation of the real wage from its steady-state value); combined with the log-linearized version of the labor supply curve (4), this yields $m c_{t}=w_{t}=c_{t}+s \cdot h_{t}$ (where $c_{t}$ and $h_{t}$ denote the log-deviations of household consumption and hours from their steady-state values). Goods-market clearing implies that we can substitute for $c_{t}$ with $y_{t}$; for $h_{t}$, we combine labor-market clearing with firm $j$ 's output demand curve to obtain $H_{t}=$ $\int_{0}^{1} H_{t}^{j} d j=\int_{0}^{1} Y_{t}^{j} d j-F C=Y_{t} \mathcal{P}_{t}-F C$, where $\mathcal{P}_{t}=\int_{0}^{1}\left(P_{t}^{j} / P_{t}\right)^{-\theta} d j$. To a first approximation,

$\log$ deviations of $\mathcal{P}_{t}$ about its steady state are equal to zero, so $h_{t}=\left(\frac{\theta-1}{\theta}\right) y_{t}$. Together, these substitutions imply that equation (10) can be re-written as:

$$
\pi_{t}=\delta E_{t} \pi_{t+1}+\lambda y_{t}
$$

where

$$
\lambda=\frac{(1-\eta)(1-\eta \delta)}{\eta}\left(1+s\left(\frac{\theta-1}{\theta}\right)\right) .
$$


The model's IS curve can be derived from the consumption Euler equation, equation (4), and the goods-market clearing condition; it is given by

$$
y_{t}=E_{t} y_{t+1}-\left(r_{t}-E_{t} \pi_{t+1}\right)
$$

where $r_{t}$ and $y_{t}$ are expressed in terms of deviations from steady state.

Finally, log-linearizing the monetary policy rule (equations 8 and 9) with the path of monetary shocks $\left\{\xi_{t}^{r}\right\}_{t=0}^{\infty}$ set equal to zero yields the two equations

$$
\bar{r}_{t}=\beta E_{t} \pi_{t+1}+\gamma y_{t} \quad \text { and } \quad r_{t}=\rho r_{t-1}+(1-\rho) \bar{r}_{t},
$$

which collapse to

$$
r_{t}=\rho r_{t-1}+(1-\rho)\left(\beta E_{t} \pi_{t+1}+\gamma y_{t}\right) .
$$

The system of log-linearized equations (11), (12), and (13) makes up our model economy. ${ }^{5}$

\subsection{Determinacy}

To assess the characteristics of the policy rule that are needed in order to ensure a determinate rational-expectations equilibrium, we rewrite the system in matrix form:

$$
E_{t} x_{t+1}=A x_{t}
$$

where $x_{t}=\left[\pi_{t}, y_{t}, r_{t-1}\right]^{\prime}$ and

$$
A=\left[\begin{array}{ccc}
\frac{1}{\delta} & -\frac{\lambda}{\delta} & 0 \\
\frac{\beta(1-\rho)-1}{\delta} & 1+\gamma(1-\rho)-\frac{\lambda(\beta(1-\rho)-1)}{\delta} & \rho \\
\frac{\beta(1-\rho)}{\delta} & \frac{(\delta \gamma-\beta \lambda)(1-\rho)}{\delta} & \rho
\end{array}\right] .
$$

Following Blanchard and Kahn (1980), a determinate (and stationary) equilibrium exists if the number of non-predetermined variables (here, two) equals the number of eigenvalues of $A$ that lie outside the unit circle. If we calibrate the structural parameters of the model, we can then determine which values of the policy-rule parameters - specifically, which value of $\beta$-will yield a determinate equilibrium for the model. ${ }^{6}$

For the structural parameter values we employ, one eigenvalue of $A$ will always lie outside the unit circle, one will always lie inside, and the third will lie inside or outside as $\beta$ varies.

\footnotetext{
${ }^{5}$ An essentially identical framework is used by Clarida, Galí, and Gertler (2000) to interpret empirical Taylor rules.

${ }^{6}$ See section A of the Appendix for a detailed discussion of how we calibrate the model.
} 
Determinacy therefore obtains when this middle eigenvalue crosses the unit circle; the value of $\beta$ for which this occurs are given in line 1 of Table 1 for various values of $\gamma$, the coefficient on the output gap in the Taylor rule. (In this case, determinacy does not depend on $\rho$, which determines the degree of interest rate smoothing in the Taylor rule.) Depending on the output-gap coefficient, the central bank must raise interest rates one-for-one (or a tiny bit less) in response to an increase in inflation in order to ensure a determinate equilibriumthat is, the relevant eigenvalue exceeds unity only if $\beta$ is around one. ${ }^{7}$ This result provides the standard justification of the Taylor principle. ${ }^{8}$

\section{The Model with Nominal Taxation}

We now incorporate a nominal tax structure into the baseline model. Specifically, we assume that all sources of household income - wages, interest, and profits received from firms - are taxed by the government at a rate equal to $F_{t}$. We focus only on the components of the model that are affected by the presence of taxation.

\subsection{The Household's Problem under Nominal Taxation}

In this version of the model, households still maximize a utility function of the form (1). However, the household's budget constraint becomes

$$
E_{t}\left[A_{t+1}^{i} / R_{t}^{f}\right]=A_{t}^{i}+\left(1-F_{t}\right)\left(W_{t} H_{t}^{i}+\operatorname{Profits}_{t}^{i}\right)+T_{t}^{i}-P_{t} C_{t}^{i}
$$

where $T_{t}^{i}$ is a lump-sum government transfer payment and $R_{t}^{f}$ is the posttax gross nominal rate of return on bonds. This posttax nominal return is defined as

$$
R_{t}^{f}=R_{t}-F_{t+1}\left(R_{t}-1\right) .
$$

\footnotetext{
${ }^{7}$ Although the values of $\gamma$ that we consider range as high as one - this is done in order to permit easy comparison with Clarida, Galí, and Gertler's (2000) work - the fact that our interest and inflation rates are expressed at quarterly rates implies that only values of $\gamma$ lower than 0.5 are likely to be empirically relevant.

${ }^{8}$ The result that $\beta$ can be slightly less than unity if the central bank places a positive weight on the output gap is a common feature of models that employ the type of pricing specification that we use here. See Woodford (2000, pp. 21-22) for a detailed discussion.

Our analysis is concerned with establishing the lower bound for $\beta$ that is consistent with equilibrium determinacy. It turns out that indeterminacy can also result if $\beta$ is sufficiently large (that is, if the central bank responds too aggressively to expected inflation) - see Woodford (2000, pp. 26-31). However, the value of $\beta$ that must be assumed in order to yield this result in this baseline model is much higher than what is likely to be practically relevant (c.f. Clarida, Galí, and Gertler, 1999, p. 1701).
} 
As before, the household is assumed to take the expected paths of $R_{t}, P_{t}, W_{t}$, profits income, and $F_{t}$ as given, and to choose $\left\{C_{t}^{i}\right\}_{t=0}^{\infty}$ and $\left\{H_{t}^{i}\right\}_{t=0}^{\infty}$ to maximize its expected utility. The Euler equation for consumption and the labor supply curve therefore become:

$$
\frac{1}{C_{t} P_{t}}=\delta E_{t}\left[\frac{R_{t}^{f}}{C_{t+1} P_{t+1}}\right] \text { and } \frac{W_{t}\left(1-F_{t}\right)}{P_{t}}=\left(H_{t}\right)^{s} C_{t} .
$$

\subsection{Production}

Introducing taxation on household income has no direct effect on the problems faced by final- and intermediate-goods producers. Specifically, final-goods producers still solve a costminimization problem of the form (7), while intermediate-goods producers solve (5). ${ }^{9}$ Note that any profits made by the intermediate-goods producers are assumed to be paid out to households, who are then taxed.

\subsection{Government}

We must now explicitly model the government's role in the model. This is kept as simple as possible: The government merely raises revenues via taxation and then rebates these revenues as a lump-sum payment to households. Hence, the government faces the following budget constraint:

$$
\int_{0}^{1} T_{t}^{i} d i=\int_{0}^{1} F_{t}\left(W_{t} H_{t}^{i}+\operatorname{Profit}_{t}^{i}+\left(R_{t-1}-1\right) A_{t-1}^{i}\right) d i .
$$

Note that if the net stock of bonds is zero (as it will be when the only bonds that are in the economy are privately issued), then the last term drops out.

\subsection{The Log-Linearized Model with Nominal Taxation}

As before, we log-linearize the model about its symmetric steady-state equilibrium in order to examine the conditions required for determinacy. The steady-state values of a number of variables are slightly different in the presence of nominal taxation; specifically, if we define the steady-state tax rate by $F_{*}$, then the symmetric steady-state equilibrium of the model is given by $Y_{*}=C_{*}=\left(\frac{\theta-1}{\theta}\right) H_{*}, H_{*}=H_{*}^{j}=\left(1-F_{*}\right)^{\frac{1}{1+s}}, \frac{W_{*}}{P_{*}}=\frac{M C_{*}^{j}}{P_{*}}=\left(\frac{\theta-1}{\theta}\right), R_{*}^{f}=\frac{\bar{\Pi}}{\delta}$, and $R_{*}=\frac{\bar{\Pi} / \delta-F_{*}}{1-F_{*}}$. (As before, we have made the assumption that $\Pi_{*}=\bar{\Pi}$.)

\footnotetext{
${ }^{9}$ In this case, the stochastic discount factor $Q_{t, t+v}$ that is used in equation (5) to discount intermediategoods producers' nominal profits equals $\frac{\delta^{v} M U_{t+v} / P_{t+v}}{M U_{t} / P_{t}} \cdot \frac{1-F_{t+v}}{1-F_{t}}$.
} 
As is evident from the preceding derivations, the only equation that is materially affected by the presence of nominal taxation is the Euler equation (17). In log-linearized form, this is given by

$$
c_{t}=E_{t} c_{t+1}-\left(r_{t}^{f}-E_{t} \pi_{t+1}\right),
$$

where $r_{t}^{f}$ - the deviation of the posttax nominal interest rate from its steady-state level - is defined by log-linearizing equation (16) to obtain

$$
r_{t}^{f}=\frac{\frac{\bar{\Pi}}{\delta}-F_{*}}{\frac{\bar{\Pi}}{\delta}} r_{t}-\frac{\frac{\bar{\Pi}}{\delta}-1}{\overline{\bar{\Pi}}} \cdot \frac{F_{*}}{1-F_{*}} E_{t} f_{t+1} .
$$

The variable $f_{t}$ in equation (20) is the log-deviation of the income-tax rate from its steadystate value. In what follows, we set $f_{t}=E_{t} f_{t+1}=0$, since this term essentially represents a shock to the model (and is therefore not relevant for assessing equilibrium determinacy). Substituting (20) into equation (19) and imposing goods-market clearing yields the model's IS curve:

$$
y_{t}=E_{t} y_{t+1}-\left(\frac{\overline{\bar{\Pi}}-F_{*}}{\overline{\bar{\Pi}}} r_{t}-E_{t} \pi_{t+1}\right) .
$$

Note that without taxation (i.e., $F_{*}=0$ ) equation (21) is identical to the IS curve for the baseline model (equation 12).

The remaining log-linearized equations - that is, the AS relation and the monetary policy rule - take the same form as those in the baseline model, and are again given by equations (11) and (13).

\subsection{Determinacy with Nominal Taxation}

Once again, we can write the full model as $E_{t} x_{t+1}=A x_{t}$, with $x_{t}$ defined - as before - as $\left[\pi_{t}, y_{t}, r_{t-1}\right]^{\prime}$. Now, however, the matrix $A$ has the form

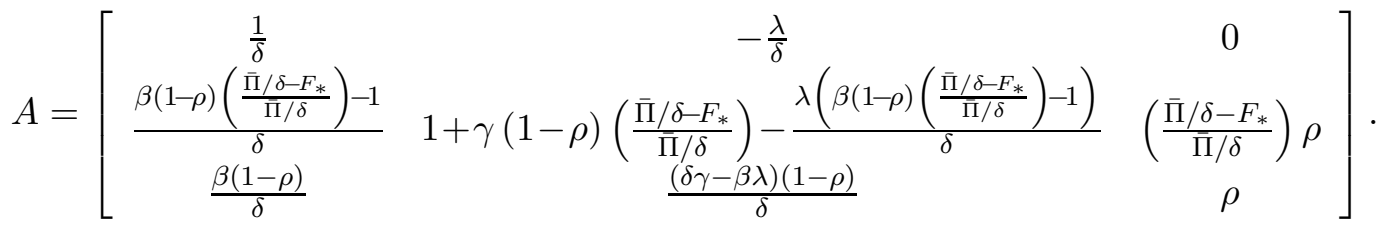

The condition for equilibrium determinacy still requires that $A$ have two eigenvalues outside the unit circle and one inside. In general, we assume the same calibrated values for the model's structural parameters as before; however, we must now also assume a value for the income-tax rate $F_{*}$. In what follows we assume a tax rate equal to 30 percent; as we 
discuss in the Appendix, this represents a reasonable estimate of the total average marginal tax rate on personal income in the United States.

As in the baseline model, the calibrated values we employ imply that one eigenvalue of $A$ is always outside the unit circle, one is always inside, and one crosses the unit circle depending on the value of $\beta$. Line 2 of Table 1 gives the value of $\beta$ that is consistent with equilibrium determinacy for various values of $\gamma$, the output gap coefficient in the Taylor rule. (As before, the value assumed for $\rho$-which determines the degree of interest-rate smoothing by the central bank - is immaterial.) As is evident from the table, the value of $\beta$ at which the model attains determinacy is considerably higher than one (the value required for determinacy in the model without taxes). In particular, for the case where $\gamma=0, \beta$ must exceed $\frac{\bar{\Pi} / \delta}{\bar{\Pi} \delta-F_{*}}$, which for our calibrated parameter values equals 1.42; this condition is relaxed slightly when the coefficient on output in the Taylor rule is positive. The requirement for determinacy is therefore much more stringent when nominal taxation is imposed.

\subsection{Discussion}

The intuition for this result is straightforward. In the simple model presented above, the interest rate that influences economic activity is the posttax real interest rate $E_{t}\left[R_{t}^{f} / \Pi_{t+1}\right]$. Hence, while the basic version of the Taylor principle states that real interest rates must rise in response to higher rates of inflation in order for monetary policy to have a stabilizing effect on the economy, the tax-adjusted version of the Taylor principle requires posttax real interest rates to rise in response to higher inflation.

The problem, however, is that nominal - not real - interest income is taxed in this economy. It is well-known that if pretax nominal interest rates rise one-for-one with an increase in inflation, a rise in inflation will cause posttax real interest rates to decline. When inflation rises, therefore, the monetary authority must increase nominal rates more than one-for-one in order to ensure that posttax real rates rise. The exact amount of the necessary increase can be seen by taking first differences of equation (20) (with the income-tax rate held constant), and then subtracting the first difference of expected inflation from either side:

$$
\Delta r_{t}^{f}-\Delta E_{t} \pi_{t+1}=\frac{\frac{\bar{\Pi}}{\delta}-F_{*}}{\frac{\bar{\Pi}}{\delta}} \Delta r_{t}-\Delta E_{t} \pi_{t+1} .
$$

Clearly, the posttax real interest rate will only rise in response to an increase in expected

inflation if $\Delta r_{t}^{f}-\Delta E_{t} \pi_{t+1}>0-$ or, equivalently, if $\frac{\bar{\Pi} / \delta-F_{*}}{\bar{\Pi} / \delta} \Delta r_{t}-\Delta E_{t} \pi_{t+1}>0$. Re-arranging 
the second inequality yields $\Delta r_{t}>\frac{\bar{\Pi} / \delta}{\bar{\Pi} / \delta-F_{*}} \Delta E_{t} \pi_{t+1}$, which implies that the posttax real interest rate will only rise following higher inflation if the pretax nominal interest rate increases by $\frac{\bar{\Pi} / \delta}{\bar{\Pi} / \delta-F_{*}}$ times more than the increase in inflation.

\subsection{The Model under an Indexed System}

It is not the presence of taxation per se that requires a larger response of nominal interest rates to inflation, but rather the fact that nominal interest income - not real - is included in the tax base. Indeed, it is simple to show that a perfectly indexed tax system (in which only real income sources are taxed) implies exactly the same statement of the Taylor principle as obtains in the model without taxation.

In our model, the introduction of an indexed tax system merely involves replacing equation (16) with

$$
E_{t}\left[\frac{R_{t}^{f}}{\Pi_{t+1}}\right]=E_{t}\left[\frac{R_{t}}{\Pi_{t+1}}\right]-F_{t+1}\left(E_{t}\left[\frac{R_{t}}{\Pi_{t+1}}\right]-1\right) .
$$

In log-linearized form, equation (24) becomes:

$$
r_{t}^{f}-E_{t} \pi_{t+1}=\frac{\frac{1}{\delta}-F_{*}}{\frac{1}{\delta}}\left(r_{t}-E_{t} \pi_{t+1}\right)+\frac{\frac{1}{\delta}-1}{\frac{1}{\delta}} \cdot \frac{F_{*}}{1-F_{*}} E_{t} f_{t+1},
$$

which, with the tax rate held constant, implies an IS curve of the form

$$
y_{t}=E_{t} y_{t+1}-\frac{\frac{1}{\delta}-F_{*}}{\frac{1}{\delta}}\left(r_{t}-E_{t} \pi_{t+1}\right) .
$$

This new IS relation (together with the original equations for the monetary-policy rule and the AS curve) once again comprise a system of the form $E_{t} x_{t+1}=A x_{t}$, where $x_{t}$ equals $\left[\pi_{t}, y_{t}, r_{t-1}\right]^{\prime}$ and where $A$ is now given by

$$
A=\left[\begin{array}{ccc}
\frac{1}{\delta} & -\frac{\lambda}{\delta} & 0 \\
\frac{(\beta(1-\rho)-1)\left(\frac{1 / \delta-F_{*}}{1 / \delta}\right)}{\delta} & 1+\gamma(1-\rho)\left(\frac{1 / \delta-F_{*}}{1 / \delta}\right)-\frac{\lambda\left((\beta(1-\rho)-1)\left(\frac{1 / \delta-F_{*}}{1 / \delta}\right)\right)}{\delta} & \left(\frac{1 / \delta-F_{*}}{1 / \delta}\right) \rho \\
\frac{\beta(\delta \gamma-\beta \lambda)(1-\rho)}{\delta} & \rho
\end{array}\right] .
$$

Evaluation of equilibrium determinacy proceeds as before, with determinacy hinging on the modulus of a critical eigenvalue that in turn depends on $\beta$. Values of $\beta$ that yield a determinate equilibrium are given in line 3 of Table 1 ; as can be seen from the table, the eigenvalue moves outside the unit circle when the coefficient on $\beta$ is approximately one. 
Hence, the original form of the Taylor principle obtains if a perfectly indexed tax system is in place.

Once again, the intuition for this result is straightforward. Determinacy requires the posttax real interest rate to rise in response to an increase in inflation. With real taxation, a rise in the pretax real interest rate always yields an increase in the posttax real interest rate, as can be seen from taking the first difference of equation (25) with the income-tax rate held constant:

$$
\Delta r_{t}^{f}-\Delta E_{t} \pi_{t+1}=\frac{\frac{1}{\delta}-F_{*}}{\frac{1}{\delta}}\left(\Delta r_{t}-\Delta E_{t} \pi_{t+1}\right)
$$

Clearly, since $\frac{1 / \delta-F_{*}}{1 / \delta}>0$, an increase in the pretax real interest rate implies an increase in the posttax rate. Hence, if the central bank raises the nominal interest rate by an amount that is even slightly greater than the (expected) rise in inflation, the posttax real interest rate will rise.

\section{Implications of an Endogenous Capital Stock}

We now wish to consider the effect on equilibrium determinacy of a second feature of the tax system; namely, the tax code's treatment of depreciation as a charge against pretax income. In order to do so, however, we require a model with an explicit capital accumulation decision. In this section, therefore, we describe a model in which households invest in the economy's capital stock; they then rent this capital to intermediate-good producing firms, who use it to produce their differentiated output. (Initially, we assume no depreciation allowances.) The description of the household and intermediate-good producing sectors changes to reflect the presence of an additional factor of production, while the government's budget constraint changes to reflect an additional source of tax revenue. (All first-order conditions for this version of the model are detailed in section B of the Appendix.)

\subsection{Households}

In the model with capital, households maximize utility subject to a capital evolution equation as well as a budget constraint. Household $i$ 's holding of the economy's aggregate capital stock evolves according to

$$
K_{t+1}^{i}=(1-\kappa) K_{t}^{i}+I_{t}^{i} \exp \left[-\frac{\chi}{2}\left(\frac{K_{t+1}^{i}}{K_{t}^{i}}-1\right)^{2}\right]
$$


where $K_{t}^{i}$ denotes household $i$ 's holding of the economy's capital stock at the beginning of period $t, I_{t}^{i}$ represents the investment spending that household $i$ undertakes during period $t$, and $\kappa$ denotes the capital stock's quarterly depreciation rate. Households face adjustment costs in altering the level of the capital stock; specifically, from any given amount of investment spending the resulting increment to the capital stock (after installation costs are accounted for $)$ is a proportion $\exp \left[-\chi / 2\left(K_{t+1}^{i} / K_{t}^{i}-1\right)^{2}\right]$ of the original expenditure.

Household $i$ 's budget constraint must now reflect the fact that households purchase goods for investment and receive taxable income from firms for the use of the capital stock. The household's budget constraint with capital is therefore:

$$
E_{t}\left[A_{t+1}^{i} / R_{t}^{f}\right]=A_{t}^{i}+\left(1-F_{t}\right)\left(R_{t}^{k} K_{t}^{i}+W_{t} H_{t}^{i}+\text { Profits }_{t}^{i}\right)+T_{t}^{i}-P_{t} C_{t}^{i}-P_{t} I_{t}^{i}
$$

The household takes as given the paths of the nominal interest rate $R_{t}$, the price level $P_{t}$, nominal wages $W_{t}$, the nominal rental rate on capital $R_{t}^{k}$, profit income, and the personal income tax rate $F_{t}$, and solves

$\max _{\left\{C_{t}^{i}, H_{t}^{i}, K_{t+1}^{i}\right\}_{t=0}^{\infty}} E_{0}\left\{\sum_{t=0}^{\infty} \delta^{t}\left[\frac{1}{1-\sigma}\left(C_{t}^{i}\right)^{1-\sigma}+\frac{1}{1+s}\left(H_{t}^{i}\right)^{1+s}\right]\right\}$ subject to eqns. (29) and (30).

The parameter $\sigma$ equals the reciprocal of the intertemporal elasticity of substitution. ${ }^{10}$

\subsection{Production}

Each monopolistically competitive intermediate-good producing firm chooses labor $H_{t}^{j}$ and capital $K_{t}^{j}$ to minimize its cost of producing output $Y_{t}^{j}$, taking as given the wage rate $W_{t}$, the rental rate $R_{t}^{k}$, and the production function. Specifically, firm $j$ solves:

$$
\min _{\left\{H_{t}^{j}, K_{t}^{j}\right\}_{t=0}^{\infty}} W_{t} H_{t}^{j}+R_{t}^{k} K_{t}^{j} \text { such that }\left(H_{t}^{j}\right)^{1-\alpha}\left(K_{t}^{j}\right)^{\alpha}-F C \geq Y_{t}^{j},
$$

where $\alpha$ is the elasticity of output with respect to capital. The cost-minimization problem implies labor- and capital-demand schedules for each firm as well as an expression for the

\footnotetext{
${ }^{10}$ In specifying the model with capital we have no longer assumed a unitary intertemporal elasticity of substitution. As Woodford (2000, p. 45) has pointed out, in models without capital the assumption of a relatively large elasticity of substitution is reasonable inasmuch as it is intended to capture the overall sensitivity of aggregate spending to changes in real interest rates. When the investment decision is modelled explicitly, however, it is more realistic to assume a lower value for $1 / \sigma$ in the utility function, which militates our treating $\sigma$ as a separate parameter.
} 
firm's marginal cost $M C_{t}^{j}$. A firm that is able to reset its price in period $t$ takes as given the marginal cost $M C_{t}^{j}$ for producing $Y_{t}^{j}$, the aggregate price level $P_{t}$, aggregate output $Y_{t}$, and the stochastic discount factor, and solves the problem given by equation (5) in section 2.2 . The representative final-good producer then aggregates intermediate output as before (see section 2.3).

\subsection{Government}

Once again, the government raises revenues by taxing income and rebates these revenues in the form of a lump-sum transfer to households. The budget constraint for the government therefore becomes:

$$
\int_{0}^{1} T_{t}^{i} d i=\int_{0}^{1} F_{t}\left(W_{t} H_{t}^{i}+R_{t}^{k} K_{t}^{i}+\operatorname{Profits}_{t}^{i}+\left(R_{t-1}-1\right) A_{t-1}^{i}\right) d i
$$

\subsection{Equilibrium}

Equilibrium is an allocation $\left\{C_{t}, I_{t}, Y_{t}, H_{t},\left\{H_{t}^{j}\right\}_{j=0}^{1}, K_{t},\left\{K_{t}^{j}\right\}_{j=0}^{1}\right\}_{t=0}^{\infty}$ and a sequence of values $\left\{\Pi_{t}, W_{t} / P_{t}, R_{t}^{k} / P_{t},\left\{M C_{t}^{j} / P_{t}\right\}_{j=0}^{1}, R_{t}^{f}, R_{t}\right\}_{t=0}^{\infty}$ that satisfy the following conditions: (i) the household solves (31); (ii) the final-good producing firm solves (7); (iii) all intermediate-good producing firms solve (32), while those that are able to reset their price solve (5); (iv) the monetary authority follows (8) and (9); (v) the goods market clears $\left(C_{t}+I_{t}=Y_{t}\right)$; and, (vi) factor markets clear $\left(H_{t}=\int_{0}^{1} H_{t}^{j} d j\right.$ and $\left.K_{t}=\int_{0}^{1} K_{t}^{j} d j\right)$. Agents are assumed to take as given the initial values $K_{0}^{i}$, and $R_{-1}$, the sequence of interest rate shocks $\left\{\xi_{t}\right\}_{t=0}^{\infty}$, and the economy's tax code $\left\{F_{t}\right\}_{t=0}^{\infty}$. (The model's first-order conditions are fully described in section B.1 of the Appendix.)

\subsection{Determinacy with Nominal Taxation and Endogenous Capital}

As before, we log-linearize the equations that characterize the economy around a symmetric steady-state equilibrium and consider the values of $\beta$ (the coefficient on inflation in the Taylor rule) that imply a determinate rational expectations equilibrium. The economy's symmetric steady-state equilibrium is described in section B.2 of the Appendix, while the log-linearized first-order conditions are given in section B.3. (The four additional parameters that must be calibrated in this model are discussed in section A.3.)

In the absence of shocks our log-linearized model can be expressed as a system of the form $E_{t} x_{t+1}=A x_{t}$, where $x_{t}$ is equal to $\left[k_{t+1}, \pi_{t}, y_{t}, k_{t}, r_{t-1}\right]^{\prime}$ and $A$ denotes a $5 \times 5$ 
matrix of parameters. However, since capital represents another non-predetermined variable, determinacy in this variant of the model requires that there be three eigenvalues outside the unit circle. As before, whether this condition is met depends on the value of $\beta$ we assume. In the fifth line of Table 1, we report the lowest value of $\beta$ that yields a determinate equilibrium in this model under nominal taxation; for comparison, in line four we give the required lower bound for $\beta$ in this model when taxation is absent (i.e., $F_{*}=0$ ). Comparing these results with the results from the benchmark model (which are given in the top two lines of the table) demonstrates that our conclusions regarding equilibrium determinacy are essentially unchanged by the introduction of an explicit investment decision. ${ }^{11}$ We next consider how this conclusion changes when depreciation allowances are added to the model.

\section{Implications of Nominal Depreciation Allowances}

Part of the payment $R_{t}^{k}$ that capital owners receive from renting out their capital stock merely reflects compensation for the depreciation of the stock from its use in production. In principle, therefore, this component of revenue is not income, and so should not be subject to taxation. In practice, the tax system accounts for this by treating depreciation as a charge against pretax income. Hence, purchasing a unit of capital yields a flow of tax credits - depreciation allowances - in addition to the usual stream of output that the additional capital can produce.

The existence of depreciation allowances provides a second, potentially important channel through which the tax system can affect the conditions necessary for equilibrium determinacy. The reason is that, for tax purposes, depreciation is computed in terms of the historical-cost value of the capital stock. Put differently, taxable income is computed by subtracting this period's depreciated capital stock (valued in purchase-date dollars) from current income (valued in current dollars). As a result, the depreciation allowances generated by a given capital investment will not be invariant to the rate of inflation; in particular, any positive rate of price inflation will erode their value, thereby making capital investment less desirable. Hence, when depreciation is subtracted from taxable income, the stimulative effect that

\footnotetext{
${ }^{11}$ As in the benchmark model, the lower bounds for $\beta$ are invariant to our choice of the interest-rate smoothing parameter $\rho$. In addition, the lower bounds for $\beta$ in the model with capital are invariant to whether contemporaneous inflation $\Pi_{t}$ or forecasted inflation $E_{t} \Pi_{t+1}$ is used in the Taylor rule. Note, however, that for extremely small — and empirically unrealistic — values of $\rho$ and $\gamma$, the upper bound on $\beta$ that is required for determinacy turns out to be significantly smaller if forecasted inflation is employed in the Taylor rule (c.f. footnote 8, above). See Carlstrom and Fuerst (2000) for a discussion of a similar result in the context of a policy rule with $\rho=0$ and $\gamma=0$.
} 
higher expected inflation has on aggregate demand (through reducing the posttax real interest rate) is partly offset by a separate contractionary effect that results from inflation's lowering the expected value of depreciation allowances. The remainder of this section assesses the impact that this additional mechanism has on our basic conclusions regarding taxation and determinacy.

\subsection{The Model with Nominal Depreciation Allowances}

In the model presented above, capital is assumed to be owned by households, who rent it out to firms for use in production. Hence, a natural way to bring depreciation allowances into the model involves rewriting the representative household's budget constraint as:

$$
\begin{aligned}
E_{t}\left[A_{t+1}^{i} / R_{t}^{f}\right]= & A_{t}^{i}+R_{t}^{k} K_{t}^{i}-F_{t}\left(R_{t}^{k} K_{t}^{i}-\sum_{v=1}^{\infty} \kappa(1-\kappa)^{v-1} P_{t-v} I_{t-v}^{i} \exp \left[-\frac{\chi}{2}\left(\frac{K_{t+1-v}^{i}}{K_{t-v}^{i}}-1\right)^{2}\right]\right) \\
& +\left(1-F_{t}\right)\left(W_{t} H_{t}^{i}+\text { Profits }_{t}^{i}\right)+T_{t}^{i}-P_{t} C_{t}^{i}-P_{t} I_{t}^{i}
\end{aligned}
$$

where the term $\sum_{v=1}^{\infty} \kappa(1-\kappa)^{v-1} P_{t-v} I_{t-v}^{i} \exp \left[-(\chi / 2)\left(K_{t+1-v}^{i} / K_{t-v}^{i}-1\right)^{2}\right]$ is the time- $t$ depreciation of all past increments to the capital stock, evaluated in purchase-price dollars. ${ }^{12}$

The only first-order condition that is affected by this extension to the model is the condition for capital supply. ${ }^{13}$ For interpreting the results that follow, it is useful to compare the log-linearized capital supply condition (that is, the user cost expression) with and without depreciation allowances. ${ }^{14}$ In the absence of depreciation allowances (and in log-linearized form), the user cost of capital equals

$$
E_{t} r_{t+1}^{k}=\left[\frac{1}{1-\delta(1-\kappa)}\right]\left(r_{t}^{f}-E_{t} \pi_{t+1}\right),
$$

\footnotetext{
${ }^{12}$ In practice, depreciation allowances are based on a legislated schedule of depreciation rates, not the true (economic) depreciation rate. By equating tax depreciation with economic depreciation (as is done in equation 34), we simplify our first-order condition for capital and greatly reduce the number of state variables in the model. However, it can be shown that the general conclusions of this section are not significantly altered if we instead use the legislated schedule of depreciation rates.

${ }^{13}$ The government's budget constraint changes in that depreciation allowances must now be deducted from the revenue raised by the government. In our setup, this affects the lump-sum transfers received by households, but does not alter any additional first-order conditions.

${ }^{14}$ For simplicity, we write these expressions under the assumption that there are no changes in tax rates (that is, $E_{t} f_{t+1}=0$ ) and that there are no capital adjustment costs (so $\chi=0$ ). The complete expression that obtains when depreciation allowances are present-and its derivation - are given in sections 1 to 3 of Appendix C.
} 
while in the presence of depreciation allowances, the log-linearized user cost equals

$$
E_{t} r_{t+1}^{k}=\left[\frac{1}{1-\delta(1-\kappa)}\right]\left(r_{t}^{f}-E_{t} \pi_{t+1}\right)+\left[\frac{1}{1-\delta(1-\kappa)} \cdot \frac{\frac{\delta}{\Pi_{*}} \kappa F_{*}}{1-\frac{\delta}{\Pi_{*}}\left(1-\kappa\left(1-F_{*}\right)\right)}\right] r_{t}^{f} .
$$

A comparison of these expressions highlights the qualitative effect of nominal depreciation allowances in this model. When depreciation allowances are absent, the interest rate that is relevant for determining aggregate demand is the posttax real interest rate. When we allow for nominal depreciation allowances, however, we introduce a separate role for the posttax nominal interest rate inasmuch as this rate determines the discounted present value of these allowances. ${ }^{15}$ As a result, a policy-induced increase in nominal interest rates depresses investment activity in two ways: by increasing the posttax real interest rate, and by increasing the posttax nominal interest rate, which reduces the value of depreciation allowances.

It is also clear from these expressions that the presence of depreciation allowances can potentially relax the conditions that must be imposed on the Taylor rule in order to ensure equilibrium determinacy. In a model where this additional channel of monetary policy transmission is absent, equilibrium determinacy can only obtain if the posttax real interest rate rises in response to an increase in expected inflation. With nominal depreciation allowances, however, equilibrium determinacy might obtain even if the posttax real interest rate fails to rise following an increase in inflation, since the contractionary effect of higher nominal interest rates independently acts to reduce aggregate demand.

Finally, a close inspection of equation (36) permits us to assess how well this model captures the quantitative effect that depreciation allowances have on the cost of capital (and, hence, on aggregate demand). In incorporating an explicit investment decision into the model, we made the standard (though unrealistic) assumption that households directly own the economy's capital stock, and therefore assumed that households directly claim tax allowances for depreciation. While this would be exactly correct for an economy that is completely comprised of sole proprietors, in reality most private capital is directly owned by corporations, implying that depreciation allowances are used in order to reduce taxable corporate income. It turns out, however, that for our calibration of the model, equation (36)

\footnotetext{
${ }^{15}$ The gross posttax nominal interest rate is the product of the gross posttax real interest rate and the gross inflation rate, both of which influence the present value of future depreciation allowances. Specifically, the posttax real interest rate determines the relative values of the tax allowances across time, while the inflation rate captures the fact that historical-cost capital expenditures (and hence depreciation allowances) are worth less in current-dollar terms when inflation is positive.
} 
provides a good approximation to the relative effects that changes in real and nominal interest rates have on the user cost of capital - specifically, it is possible to demonstrate that the relative effects that obtain in our model are very close to those implied by a Hall-Jorgenson user cost expression that is calibrated using the tax rate on corporate income. ${ }^{16}$ This suggests that our principal results would be unaffected by explicitly modelling a separate corporate sector.

\subsection{Conditions for Determinacy and Stability}

We now consider the values of $\beta$ (the weight given to expected inflation in the Taylor rule) that are necessary for determinacy and stability in our extended model; these are summarized in Table 2 for a variety of cases. As is evident from the table, introducing nominal depreciation allowances can significantly affect the value of $\beta$ that is required for a determinate equilibrium. In addition, equilibrium stability - which was never an issue in the other models we examined - becomes relevant when we introduce nominal depreciation allowances; furthermore, the assumed value of $\rho$ (the interest-rate smoothing coefficient in the Taylor rule) now also has an effect on the threshold for determinacy in the model.

Results with No Weight on Output: We first examine the results that obtain when there is no weight on the output gap in the Taylor rule (that is, $\gamma=0$ ) and a moderate degree of interest-rate smoothing $(\rho=0.5)$. As expected, we find that introducing nominal depreciation allowances does indeed lower the value of $\beta$ that is required for equilibrium determinacy, though only by a small amount (the new value of $\beta$ equals 1.31 , which is still much greater than unity). However, the conditions for a determinate and stable rational expectations equilibrium turn out to be unchanged relative to the model without nominal depreciation allowances. Loosely speaking, while the presence of nominal depreciation allowances does in fact take some of the burden of restoring equilibrium off of the real interest rate, a rise in posttax real rates following an increase in inflation is still required in order to ensure the existence of a stable rational expectations equilibrium.

Intuitively, stability becomes an issue in this model because the level of inflation has real effects on aggregate demand and capital formation. If posttax real interest rates do not rise sufficiently following an increase in inflation, then some portion of the increase in inflation will persist. This in turn keeps the level of nominal interest rates elevated, which depresses activity even if the posttax real interest rate returns to a level that is close to its

\footnotetext{
${ }^{16}$ See section 4 of Appendix $\mathrm{C}$ for details.
} 
steady state. In addition, the higher real rental rates that result from the higher nominal interest rates reduce the optimal capital stock and raise real marginal costs. ${ }^{17} \mathrm{~A}$ vicious circle then obtains as higher marginal costs further raise inflation and nominal interest rates (while leaving real interest rates near their steady-state level), thus depressing output and raising the real rental rate even more. This "implosive" solution is unique, even though it drives the economy further and further away from its steady-state equilibrium. Hence, while our baseline model implied that an increase in the posttax real interest rate following an increase in inflation was enough to ensure a determinate rational expectations equilibrium, with nominal depreciation allowances, an increase in posttax real rates is also needed to ensure the stability of this equilibrium. ${ }^{18}$

Results with a Positive Weight on Output: In the models we considered earlier, the presence of a long-run tradeoff between inflation and output implied that placing a positive weight on the output gap in the Taylor rule could lower, albeit slightly, the weight on inflation that was required for equilibrium determinacy (see footnote 7). In a model with nominal depreciation allowances, however, the opposite result obtains: Placing a positive weight on the output gap in the Taylor rule raises the required coefficient on expected inflation by a non-trivial amount.

The reason this occurs can be seen if we consider the case where the central bank raises nominal interest rates by just enough to yield an increase in the posttax real rate after a rise in inflation. In an economy where depreciation allowances are absent, this is enough to ensure determinacy. But when depreciation allowances are present, the rise in nominal rates itself lowers aggregate demand by increasing the user cost of capital. To the extent that policymakers care about the output gap-i.e., to the extent that $\gamma$ is positive in the Taylor rule - this decline in output induces the central bank to lower the policy rate. In such an economy, therefore, the appropriate response to inflation must be one which ensures that

\footnotetext{
${ }^{17}$ Although lower output reduces consumption and leisure - thereby increasing the supply of labor hoursthe rise in hours is not enough to offset the decline in the capital stock. Hence, output falls on net. Moreover, while the increased supply of hours reduces the real wage, this is outweighed by the increase in the real rental rate, so a net increase in real marginal costs results.

${ }^{18}$ Of course, the realism of this result is open to question. While the Taylor rule provides a convenient modelling tool for summarizing the quotidian conduct of monetary policy, we suspect that a "stagflation" scenario such as that just described would likely result in a more aggressive move against inflation by policymakers. Thus, a sensible discussion of policy when the economy is significantly off its steady-state path is probably beyond the scope of this type of model.
} 
a rise in the posttax real interest rate obtains despite the offset to nominal interest rates that occurs because policymakers react to lower output. This amounts to a more aggressive policy response to inflation; specifically, one that scales up the required increase in nominal rates after a rise in inflation by a factor that depends positively on the coefficient on output in the Taylor rule as well as on the effect that nominal rates have on depreciation allowances (and thus on aggregate demand). In particular, for the model considered here, a coefficient of 0.125 on the output gap in the Taylor rule (with $\rho=0.5$ ) requires an inflation coefficient of 1.7 , while an output-gap coefficient of 0.25 requires a weight of around 2.0 on inflation. ${ }^{19}$

Effect of Interest-Rate Smoothing on Determinacy: As is also evident from Table 2, the assumed value of $\rho$ in the Taylor rule - which determines the degree of interest-rate smoothing - has a noticeable influence on the threshold value of $\beta$ that is required for a determinate equilibrium in this model. Interestingly, however, the conditions for stability do not change. This result obtains because larger values of $\rho$ (more smoothing) imply a smaller rise in nominal interest rates in response to an increase in inflation. Consequently, the contractionary effect on output that occurs from the interplay of nominal interest rates and depreciation allowances is lessened, as is the ability of depreciation allowances to relax the conditions that are required for determinacy. By contrast, the stability of equilibrium depends on the long-run properties of the policy rule. Hence, the value of $\beta$ required for stability is unaffected by changes in $\rho^{20}$

\section{Conclusions}

This paper has demonstrated that the condition required in order for equilibrium determinacy to obtain in a sticky-price monetary business cycle model is significantly affected by the presence of nominal income taxation. In particular, for realistic levels of income taxation, the coefficient on inflation in a Taylor-type monetary policy rule must lie well above unity, implying that the standard statement of the Taylor principle no longer provides a satisfactory

\footnotetext{
${ }^{19}$ Note that the conditions for a determinate equilibrium are again slightly weaker than those for a determinate and stable equilibrium; the intuition for this result is similar to that for the version of the model with $\gamma=0$

${ }^{20}$ Because stability is a long-run property, the lower bound on $\beta$ that is required for a determinate and stable rational expectations equilibrium is invariant to whether $\Pi_{t}$ or $E_{t} \Pi_{t+1}$ is used in the policy rule. The condition for determinacy is, however, altered in two ways when $\Pi_{t}$ is used: First, we can always obtain a determinate equilibrium (even for low values of $\rho$ and $\gamma$ ); and second, the lower bound of $\beta$ that is required for determinacy is slightly higher.
} 
precept for ensuring real determinacy in economies of this sort. Importantly, this interaction between the tax system and the transmission of monetary policy is present - and significanteven at relatively low levels of inflation.

An interesting implication of this finding relates to the interpretation of historical estimates of Taylor rules for the United States. For example, Orphanides (2002) has found that estimation of the U.S. Taylor rule using real-time data from 1969 to 1979 yields a lagged inflation coefficient of 1.52 , with a standard error equal to 0.24 . As this is comfortably above the level required in order for equilibrium determinacy to obtain in a standard theoretical setup, Orphanides argues that ignorance of the Taylor principle probably did not contribute to macroeconomic instability in the 1970s. This conclusion is weakened, however, when we note that this point estimate lies less than one standard deviation above the lowest level needed for determinacy in a model with nominal taxation, and almost always lies below the level required for determinacy and stability in a model that incorporates nominal depreciation allowances. We would argue, therefore, that the effect of nominal taxation that we find in our theoretical setup is, in quantitative terms, potentially quite important for interpreting the historical conduct of monetary policy.

Our result also implies that the pursuit of a common cross-country monetary policy (such as that currently undertaken by the European Central Bank) may be rendered more difficult if there is insufficient harmonization of national tax codes. Rates of income taxation that differ significantly across countries could imply that equilibrium determinacy holds for some members of a monetary union, but not for others; in any event, real posttax rates of return will differ even with a common pretax nominal interest rate and common inflation rate.

Finally, even if depreciation allowances are absent, the taxation of nominal interest income implies that there is a systematic connection between the level of inflation and the existence of a real distortion in the economy. The presence of this distortion (which takes the form of a wedge between the equilibrium real interest rate and the marginal rate of substitution faced by consumers) suggests that standard welfare-theoretic assessments of optimal monetary policy might be misleading; in particular, the costs of inflation in this sort of model are no longer confined to the relative-price distortions that arise because prices are sticky. The existence of this additional consideration could well influence one's assessment of the relative merits of different types of monetary-policy regimes (such as policies that allow for discretion in lieu of full commitment). We leave further examination of these interesting issues for future research. 
In the end, therefore, the conclusion that we draw from these results is that our understanding of the optimal conduct of monetary policy is likely to be significantly advanced by employing richer and more realistic theoretical specifications. As we have demonstrated, even a very marginal improvement to the standard framework can significantly alter what has been viewed as a basic message of the modern literature on monetary policy. We suspect that many more such improvements - and surprises - are possible. 


\section{References}

[1] Abowd, John M. and David Card (1989). "On the Covariance Structure of Earnings and Hours Changes." Econometrica, 57, 411-445.

[2] Blanchard, Olivier Jean and Charles M. Kahn (1980). "The Solution of Linear Difference Models under Rational Expectations." Econometrica, 48, 1305-1311.

[3] Carlstrom, Charles T. and Timothy S. Fuerst (2000). "The Role of Investment Spending in Sticky Price Models." Manuscript (November 2nd draft).

[4] Clarida, Richard, Jordi Galí, and Mark Gertler (1999). "The Science of Monetary Policy: A New Keynesian Perspective." Journal of Economic Literature, 37, 1661-1707.

[5] Clarida, Richard, Jordi Galí, and Mark Gertler (2000). "Monetary Policy Rules and Macroeconomic Stability: Evidence and Some Theory." Quarterly Journal of Economics, $115,147-180$.

[6] Cohen, Darrel, Kevin A. Hassett, and R. Glenn Hubbard (1999). "Inflation and the User Cost of Capital: Does Inflation Still Matter?" Chapter 5 in Martin Feldstein, ed., The Costs and Benefits of Price Stability. Chicago: University of Chicago Press.

[7] Feldstein, Martin (1982). "Inflation, Capital Taxation, and Monetary Policy." Chapter 7 in Robert E. Hall, ed., Inflation: Causes and Effects. Chicago: University of Chicago Press.

[8] Gordon, Roger H. and Burton G. Malkiel (1981). "Corporation Finance." In Henry Aaron and Joseph Pechman, eds., How Taxes Affect Economic Behavior. Washington: Brookings Institution.

[9] Kimball, Miles S. (1995). "The Quantitative Analytics of the Basic Neomonetarist Model." Journal of Money, Credit, and Banking, 27, 1241-1277.

[10] Orphanides, Athanasios (2002). "Monetary Policy Rules and the Great Inflation." Federal Reserve Board, Finance and Economics Discussion Series Paper No. 2002-08.

[11] Woodford, Michael (2000). "A Neo-Wicksellian Framework for the Analysis of Monetary Policy." Chapter 4 of Interest and Prices, manuscript (September 29th draft). 


\section{A Calibrated Parameter Values}

This Appendix provides more details on the values used to calibrate the various versions of the model.

\section{A.1 Common Structural Parameters}

A number of structural parameters are common to all versions of the model; these are summarized in the table below.

Table A: Calibrated Values of Common Structural Parameters

\begin{tabular}{cll}
\hline \hline Parameter & Description & Value \\
\hline \multirow{3}{*}{$\bar{\Pi}$} & Households' discount factor & 0.99 \\
$\theta$ & Inflation target & 1.005 \\
$(1-\eta)$ & Elasticity of substitution of intermediates & 11 \\
$s$ & Probability firm can reset price & 0.25 \\
& Labor supply elasticity & 2.75 \\
\hline \hline
\end{tabular}

The values of $\delta$ and $\bar{\Pi}$ are expressed at a quarterly rate (not annual). The calibrated value for $\delta$ is taken from Clarida, Galí, and Gertler (2000, p.170); $\bar{\Pi}$ is chosen so as to imply an inflation target of 2 percent at an annual rate.

Our value of $\theta$ is selected so as to yield an equilibrium markup of 10 percent (which Kimball, 1995, argues is consistent with existing empirical data), while our value for $\eta$ implies that the average length of time over which prices remain fixed is four quarters. Finally, we choose a value for the labor supply elasticity that yields an elasticity of inflation with respect to output ( $\lambda$ in equation 11) that is similar to what Clarida, Galí, and Gertler (2000) assume in their work. ${ }^{21}$ For the model without taxes, this choice of structural parameters implies that $\lambda$ equals 0.30 (identical to the value used by Clarida, et al.); when taxes are added to the model, this coefficient rises slightly (to 0.31 ).

\footnotetext{
${ }^{21}$ While this labor supply elasticity is higher than what is commonly employed by RBC modellers, it is quite consistent with the range of values found in the micro-labor literature (see, for example, Abowd and Card, 1989, table 10); it also yields a much more realistic implication for the representative consumer's marginal expenditure share of leisure (c.f. the discussion in Kimball, 1995, pp. 1267-69). In any event, our choice of labor supply elasticity is relatively unimportant for our purposes, since our key results are robust to our choice of $\lambda$ (which is the only model parameter that depends on $s$ ).
} 
One structural parameter that we implicitly calibrate in the model without capital is the intertemporal elasticity of substitution of consumption. As is evident from our equation (1), we have assumed a unitary elasticity of substitution for this version of the model, which is again identical to what Clarida, Galí, and Gertler (2000) assume. ${ }^{22}$

\section{A.2 Calibrating the Income-Tax Rate}

We seek a measure of the average marginal tax rate on personal income. For the United States, tabulations from the Statistics of Income categorize taxpayers by their marginal rates and adjusted gross income (AGI); this allows us to compute the Federal average marginal rate by using these AGI figures to weight the tabulated marginal rates. However, we do not have comparable data that would allow us to compute the average marginal income tax rate levied by state and local governments. We therefore compute an average rate by taking the ratio of personal income tax payments to nominal GDP excluding government capital consumption (these data are taken from the U.S. National Income and Product Accounts), and then sum these two rates to yield a proxy for the total average marginal tax rate on personal income.

From 1970 to 1997, this measure of the average marginal rate fluctuates between about 25 and 30 percent, with an average of 27.5 percent. $^{23}$ We use the upper end of this range (i.e., 30 percent) to calibrate the model; this choice is informed by three considerations. First, our estimate of the average marginal tax rate levied by state and local governments (which is computed as an average rate) will tend to understate the true marginal tax rate to the extent that these income tax systems are progressive. Second, the distribution of wealth (and, hence, of asset income) is likely skewed in favor of higher-income households; as a result, the marginal tax rate on interest income is probably higher than the average marginal rate on all income. ${ }^{24}$ Finally, our computed average marginal rate is around 30 percent from roughly the mid-1970s to the mid-1980s. As the question of equilibrium determinacy is particularly interesting over this period, calibrating our model with an average marginal

\footnotetext{
${ }^{22}$ See also footnote 10 , above.

${ }^{23}$ Our measure of the Federal rate ranges from 23 to 29 percent, while the state and local tax measure ranges from one to two percent. (In 1978 and from 1980 to 1982, the Statistics of Income do not provide the necessary tabulations; our estimates of the Federal tax rate in those years is therefore computed with a linear interpolation.)

${ }^{24} \mathrm{~A}$ more complicated model could impose different average marginal tax rates on different types of income. It turns out, however, that only the rate on asset income is relevant (in particular, as long as the marginal tax rates on wage and other types of income are expected to be constant over time, they will not enter the log-linearized system).
} 
rate that is relevant for these years is appealing.

An alternative way to measure the relevant marginal tax rate for asset income involves comparing the market returns on taxable and tax-free bonds of similar riskiness. Gordon and Malkiel (1981) survey several studies that perform this type of calculation, and conclude that a reasonable estimate of the implicit tax rate on interest income from long-term debt is around 25 percent. However, Gordon and Malkiel also conclude that the implicit tax rate on short-term debt - which is more relevant for our purposes - is somewhat higher (around 42 percent). ${ }^{25}$ These results also suggest that our assumed average marginal tax rate of 30 percent is not unreasonable, particularly if we seek to capture the experience of the 1970s.

\section{A.3 Parameters for the Model with Endogenous Capital}

Adding capital to the model requires us to calibrate four additional parameters; these are summarized in the following table.

Table B: Structural Parameter Values in the Model with Capital

\begin{tabular}{clc}
\hline \hline Parameter & Description & Value \\
\hline & Elasticity of output with respect to capital & 0.3 \\
$\alpha$ & Intertemporal elasticity of substitution & 0.2 \\
$\sigma^{-1}$ & Depreciation rate & 0.02 \\
$\kappa$ & Curvature parameter in adjustment cost function & 500 \\
$\chi$ & & \\
\hline \hline
\end{tabular}

The values we employ for the first three parameters are chosen so as to match Kimball's (1995) preferred calibration, and are relatively uncontroversial. (Note that depreciation, $\kappa$, is expressed at a quarterly rate, so our assumed value equals 8 percent per year.) For $\chi$, we choose a value that gives our capital adjustment cost function the same curvature properties as Kimball's specification.

\footnotetext{
${ }^{25}$ The data for the studies that use long-term debt cover the 1960s and 1970s, while the data for the studies that consider rates of return on short-term debt cover the 1960s only. Note that, after 1963, the top marginal Federal tax rate on (unearned) personal income remained relatively constant until 1981.
} 


\section{B Appendix to the Model with Endogenous Capital}

\section{B.1 First-Order Conditions}

The household's utility maximization problem (equation 31) yields an Euler equation and supply schedules for labor and capital:

$$
\begin{gathered}
\frac{1}{C_{t}^{\sigma} P_{t}}=\delta E_{t}\left[\frac{R_{t}^{f}}{C_{t+1}^{\sigma} P_{t+1}}\right] \\
\frac{W_{t}\left(1-F_{t}\right)}{P_{t}}=H_{t}^{s} C_{t}^{\sigma}, \text { and } \\
E_{t}\left[\frac{R_{t+1}^{k}\left(1-F_{t+1}\right)}{P_{t+1}}\right]=E_{t}\left[\frac{R_{t}^{f}}{\Pi_{t+1}} \exp \left[\frac{\chi}{2}\left(\frac{K_{t+1}}{K_{t}}-1\right)^{2}\right]\left(1+\chi\left(\frac{K_{t+1}}{K_{t}}-(1-\kappa)\right)\left(\frac{K_{t+1}}{K_{t}}-1\right)\right)\right] \\
-E_{t}\left[\exp \left[\frac{\chi}{2}\left(\frac{K_{t+2}}{K_{t+1}}-1\right)^{2}\right]\left((1-\kappa)+\chi\left(\frac{K_{t+2}}{K_{t+1}}-(1-\kappa)\right)\left(\frac{K_{t+2}}{K_{t+1}}-1\right) \frac{K_{t+2}}{K_{t+1}}\right)\right]
\end{gathered}
$$

where the variable $R_{t}^{f}$ is defined by equation (16).

The final-good producing firm's cost-minimization problem (7) yields a demand function for each of the intermediate goods:

$$
Y_{t}^{j}=Y_{t}\left(P_{t}^{j} / P_{t}\right)^{-\theta}
$$

The demand functions for the intermediate goods imply that the competitive price $P_{t}$ for the final (actual) good is defined implicitly as:

$$
P_{t}=\left(\int_{0}^{1}\left(P_{t}^{j}\right)^{1-\theta} d z\right)^{\frac{1}{1-\theta}}
$$

The intermediate-good producing firms' cost-minimization problem (32) yields factor demand schedules for each firm; these have the form:

$$
\begin{aligned}
H_{t}^{j} & =\left(\frac{1-\alpha}{\alpha}\right)^{\alpha}\left(Y_{t}^{j}+F C\right)\left(\frac{R_{t}^{k} / P_{t}}{W_{t} / P_{t}}\right)^{\alpha} \text { and } \\
K_{t}^{j} & =\left(\frac{\alpha}{1-\alpha}\right)^{1-\alpha}\left(Y_{t}^{j}+F C\right)\left(\frac{W_{t} / P_{t}}{R_{t}^{k} / P_{t}}\right)^{1-\alpha} .
\end{aligned}
$$


In addition, this problem implies a marginal cost function (which is identical for all firms) that is given by:

$$
\frac{M C_{t}^{j}}{P_{t}}=\left(\frac{W_{t} / P_{t}}{1-\alpha}\right)^{1-\alpha}\left(\frac{R_{t}^{k} / P_{t}}{\alpha}\right)^{\alpha} .
$$

The intermediate-good producing firm's profit-maximization problem (5) implicitly defines an optimal price $P_{t+1}^{j}$ for firms who do change their prices in period $t$; this is expressed as:

$$
P_{t}^{j}=\frac{\sum_{k=0}^{\infty} \eta^{k} E_{t}\left[Q_{0, t} M C_{t+k}^{j} \theta Y_{t+k}\right]}{\sum_{k=0}^{\infty} \eta^{k} E_{t}\left[Q_{0, t}(\theta-1) Y_{t+k}\right]} .
$$

This is identical to the first-order condition given by equation (6).

Finally, goods-market clearing implies that $C_{t}+I_{t}=Y_{t}$, where investment $I_{t}$ is defined as

$$
I_{t}=\exp \left[-\frac{\chi}{2}\left(\frac{K_{t+1}}{K_{t}}-1\right)^{2}\right]\left(K_{t+1}-(1-\kappa) K_{t}\right) \text {. }
$$

\section{B.2 Steady-state Equilibrium}

In deriving the model's steady-state equilibrium, we first note that the steady-state value of the inflation rate, $\Pi_{*}$, is assumed to equal the central bank's inflation target, $\bar{\Pi}$. The steadystate values of all other variables in the model are functions of the model's parameters as well as of the steady-state inflation rate and the steady-state value of the tax variable, $F_{*}$.

From equations (16) and (37), the steady-state pretax and posttax nominal interest rates are given by:

$$
\begin{aligned}
R_{*} & =\left(\frac{\bar{\Pi}}{\delta}-F_{*}\right) \frac{1}{1-F_{*}} \text { and } \\
R_{*}^{f} & =\frac{\bar{\Pi}}{\delta} .
\end{aligned}
$$

The steady-state value of real marginal cost is given by the inverse of the markup, while equations (39) and (44) imply that the steady-state values of the factor prices are given by:

$$
\begin{aligned}
\frac{M C_{*}^{j}}{P_{*}} & =\frac{M C_{*}}{P_{*}}=\frac{\theta-1}{\theta} \\
\frac{R_{*}^{k}}{P_{*}} & =\left(\frac{1}{1-F_{*}}\right)\left(\frac{1}{\delta}-(1-\kappa)\right) \\
\frac{W_{*}}{P_{*}} & =(1-\alpha)\left(\frac{M C_{*}}{P_{*}}\right)^{\frac{1}{1-\alpha}}\left(\frac{\alpha}{R_{*}^{k} / P_{*}}\right)^{\frac{\alpha}{1-\alpha}}=(1-\alpha)\left(\frac{\theta-1}{\theta}\right)^{\frac{1}{1-\alpha}}\left(\frac{\alpha\left(1-F_{*}\right)}{\frac{1}{\delta}-(1-\kappa)}\right)^{\frac{\alpha}{1-\alpha}}
\end{aligned}
$$


The steady-state ratios $\frac{H_{*}^{j}}{Y_{*}}=\frac{H_{*}}{Y_{*}}, \frac{K_{*}}{Y_{*}}, \frac{I_{*}}{Y_{*}}$, and $\frac{C_{*}}{Y_{*}}$ can be derived from equations (46), (42), (43), and the market-clearing condition. This yields:

$$
\begin{aligned}
\frac{H_{*}^{j}}{Y_{*}} & =\frac{H_{*}}{Y_{*}}=\left(\frac{\theta}{\theta-1}\right)\left(\frac{1-\alpha}{\alpha}\right)^{\alpha}\left(\frac{R_{*}^{k} / P_{*}}{W_{*} / P_{*}}\right)^{\alpha}, \\
\frac{K_{*}}{Y_{*}} & =\left(\frac{\theta}{\theta-1}\right)\left(\frac{\alpha}{1-\alpha}\right)^{1-\alpha}\left(\frac{W_{*} / P_{*}}{R_{*}^{k} / P_{*}}\right)^{1-\alpha}, \\
\frac{I_{*}}{Y_{*}} & =\kappa \cdot \frac{K_{*}}{Y_{*}}=\kappa\left(\frac{\theta}{\theta-1}\right)\left(\frac{\alpha}{1-\alpha}\right)^{1-\alpha}\left(\frac{W_{*} / P_{*}}{R_{*}^{k} / P_{*}}\right)^{1-\alpha}, \\
\frac{C_{*}}{Y_{*}} & =1-\frac{I_{*}}{Y_{*}}=1-\kappa\left(\frac{\theta}{\theta-1}\right)\left(\frac{\alpha}{1-\alpha}\right)^{1-\alpha}\left(\frac{W_{*} / P_{*}}{R_{*}^{k} / P_{*}}\right)^{1-\alpha} .
\end{aligned}
$$

Equations (52) and (55), together with the steady-state version of equation (38), yield the steady-state solution for real output:

$$
\begin{aligned}
Y_{*} & =\frac{\left(W_{*} / P_{*}\right)^{\frac{1}{1+s}}\left(1-F_{*}\right)^{\frac{1}{1+s}}}{\left(H_{*} / Y_{*}\right)^{\frac{s}{1+s}}\left(C_{*} / Y_{*}\right)^{\frac{1}{1+s}}}\left(W_{*} / P_{*}\right)^{\frac{1}{1+s}}\left(1-F_{*}\right)^{\frac{1}{1+s}} \\
= & \frac{\left.\frac{s}{\theta-1}\right)^{\frac{s}{1+s}}\left(\frac{1-\alpha}{\alpha}\right)^{\frac{s \alpha}{1+s}}\left(\frac{R_{*}^{k} / P_{*}}{W_{*} / P_{*}}\right)^{\frac{s \alpha}{1+s}}\left(1-\kappa\left(\frac{\theta}{\theta-1}\right)\left(\frac{\alpha}{1-\alpha}\right)^{1-\alpha}\left(\frac{W_{*} / P_{*}}{R_{*}^{k} / P_{*}}\right)^{1-\alpha}\right)^{\frac{1}{1+s}}}{\left(\frac{1}{\theta-1}\right.}
\end{aligned}
$$

Together with equations (52) through (55), equation (56) yields solutions for the steady-state values of $H_{*}, K_{*}, I_{*}$, and $C_{*}$.

\section{B.3 Log-Linearized First-Order Conditions}

Equations (37), (38), and (39) from the household's problem log-linearize to:

$$
\begin{gathered}
c_{t}=E_{t} c_{t+1}-\frac{1}{\sigma}\left(r_{t}^{f}-E_{t} \pi_{t+1}\right), \\
w_{t}=\frac{F_{*}}{1-F_{*}} f_{t}+\sigma \cdot c_{t}+s \cdot h_{t}, \text { and } \\
E_{t} r_{t+1}^{k}=\left[\frac{F_{*}}{1-F_{*}}\right] f_{t+1}+\left[\frac{1}{1-\delta(1-\kappa)}\right]\left(r_{t}^{f}-E_{t} \pi_{t+1}\right)-\left[\frac{\chi \cdot \kappa}{1-\delta(1-\kappa)}\right]\left(\delta E_{t} k_{t+2}-(1+\delta) k_{t+1}+k_{t}\right),
\end{gathered}
$$

where $r_{t}^{f}$ is defined in equation (20).

The economy's factor demands (equations 42 and 43), which are obtained from the intermediate-good producing firms' cost-minimization problem, linearize to:

$$
h_{t}=\left(\frac{\theta-1}{\theta}\right) y_{t}-\alpha w_{t}+\alpha r_{t}^{k}, \text { and }
$$




$$
k_{t}=\left(\frac{\theta-1}{\theta}\right) y_{t}+(1-\alpha) w_{t}-(1-\alpha) r_{t}^{k}
$$

while marginal cost (equation 44) linearizes to:

$$
m c_{t}=(1-\alpha) w_{t}+\alpha r_{t}^{k}
$$

The log-linearization of equation (45) from the intermediate-good producing firms' profit-maximization problem implies that deviations of the gross inflation rate from its steady-state value evolves according to:

$$
\pi_{t}=\delta E_{t} \pi_{t+1}+\frac{(1-\eta)(1-\eta \delta)}{\eta} E_{t} m c_{t+1}
$$

The economy's goods market clearing condition log-linearizes to

$$
y_{t}=\frac{C_{*}}{Y_{*}} c_{t}+\frac{I_{*}}{Y_{*}} i_{t}
$$

where

$$
i_{t}=\left(\frac{1}{\kappa}\right) k_{t+1}-\left(\frac{1-\kappa}{\kappa}\right) k_{t}
$$




\section{Appendix to the Model with Depreciation Allowances}

\section{C.1 First-Order Conditions}

The first-order conditions for consumption and labor supply implied by the household's utility maximization problem are still given by equations (37) and (38) of section B.1. However, the capital supply equation is now given by:

$$
\begin{aligned}
& E_{t}\left[\frac{R_{t+1}^{k}\left(1-F_{t+1}\right)}{P_{t+1}}\right] \\
& =E_{t}\left[\frac{R_{t}^{f}}{\Pi_{t+1}}\left(1-\exp \left[\frac{\chi}{2}\left(\frac{K_{t+1}}{K_{t}}-1\right)^{2}\right] P D V_{t}^{\kappa}\right) \times\right. \\
& \left.\quad \exp \left[\frac{\chi}{2}\left(\frac{K_{t+1}}{K_{t}}-1\right)^{2}\right]\left(1+\chi\left(\frac{K_{t+1}}{K_{t}}-(1-\kappa)\right)\left(\frac{K_{t+1}}{K_{t}}-1\right)\right)\right] \\
& +E_{t}\left[\frac{R_{t}^{f}}{\Pi_{t+1}} P D V_{t}^{\kappa} \chi\left(\frac{K_{t+1}}{K_{t}}-(1-\kappa)\right)\left(\frac{K_{t+1}}{K_{t}}-1\right)\right] \\
& -E_{t}\left[\left(1-\exp \left[\frac{\chi}{2}\left(\frac{K_{t+2}}{K_{t+1}}-1\right)^{2}\right] P D V_{t+1}^{\kappa}\right)\right. \\
& \left.\quad \times \exp \left[\frac{\chi}{2}\left(\frac{K_{t+2}}{K_{t+1}}-1\right)^{2}\right]\left((1-\kappa)+\chi\left(\frac{K_{t+2}}{K_{t+1}}-(1-\kappa)\right)\left(\frac{K_{t+2}}{K_{t+1}}-1\right) \frac{K_{t+2}}{K_{t+1}}\right)\right] \\
& -E_{t}\left[P D V_{t+1}^{\kappa} \chi\left(\frac{K_{t+2}}{K_{t+1}}-(1-\kappa)\right)\left(\frac{K_{t+2}}{K_{t+1}}-1\right) \frac{K_{t+2}}{K_{t+1}}\right] .
\end{aligned}
$$

The variable $P D V_{t}^{\kappa}$ is the present discounted value of the future tax savings that households will receive from their depreciation allowances; this is given by

$$
P D V_{t}^{\kappa}=E_{t}\left\{\sum_{v=1}^{\infty} \frac{\delta^{v} M U_{t+v} / P_{t+v}}{M U_{t} / P_{t}} \kappa(1-\kappa)^{v-1} F_{t+v}\right\},
$$

where $M U_{t}$ denotes the marginal utility of consumption, $C_{t}^{-\sigma}$. All other first-order conditions in the model remain unchanged by the introduction of nominal depreciation allowances. ${ }^{26}$

\section{C.2 Steady-state Equilibrium}

From equation (64), we obtain that the steady-state present discounted value of future tax savings is equal to

$$
P D V_{*}^{\kappa}=F_{*} \cdot \frac{\kappa}{\frac{\Pi_{*}}{\delta}-(1-\kappa)},
$$

\footnotetext{
${ }^{26}$ Note that equation (63) reduces to the Hall-Jorgenson user cost formula if there are no adjustment costs, interest, tax, and inflation rates are constant over time, and corporate and personal tax rates are equal. (We consider the quantitative effect of relaxing the last assumption in section C.4, below.)
} 
while from equation (63) we find that the steady-state value of the real rental rate is:

$$
\begin{aligned}
\frac{R_{*}^{k}}{P_{*}} & =\frac{1-P D V_{*}^{\kappa}}{1-F_{*}} \cdot\left(\frac{1}{\delta}-(1-\kappa)\right) \\
& =\frac{1}{1-F_{*}} \cdot \frac{\frac{1}{\delta}-(1-\kappa)}{\frac{\Pi_{*}}{\delta}-(1-\kappa)} \cdot\left(\frac{\Pi_{*}}{\delta}-\left(1-\kappa\left(1-F_{*}\right)\right)\right) .
\end{aligned}
$$

This implies that the steady-state value of the real wage is:

$$
\begin{aligned}
\frac{W_{*}}{P_{*}} & =(1-\alpha)\left(\frac{M C_{*}}{P_{*}}\right)^{\frac{1}{1-\alpha}}\left(\frac{\alpha}{R_{*}^{k} / P_{*}}\right)^{\frac{\alpha}{1-\alpha}} \\
& =(1-\alpha)\left(\frac{\theta-1}{\theta}\right)^{\frac{1}{1-\alpha}}\left(\frac{\alpha\left(1-F_{*}\right)}{\frac{\Pi_{*}}{\delta}-\left(1-\kappa\left(1-F_{*}\right)\right)}\right)^{\frac{\alpha}{1-\alpha}}\left(\frac{\frac{\Pi_{*}}{\delta}-(1-\kappa)}{\frac{1}{\delta}-(1-\kappa)}\right)^{\frac{\alpha}{1-\alpha}} .
\end{aligned}
$$

The steady-state ratios $\frac{H_{*}^{j}}{Y_{*}}=\frac{H_{*}}{Y_{*}}, \frac{K_{*}}{Y_{*}}, \frac{I_{*}}{Y_{*}}$, and $\frac{C_{*}}{Y_{*}}$ are still given by equations (52) to (55), where the new steady-state real wage and rental rates (equations 66 and 67) are used.

\section{C.3 Log-Linearized First-Order Conditions}

Equation (63) log-linearizes to:

$$
\begin{aligned}
E_{t} r_{t+1}^{k} & =\left[\frac{F_{*}}{1-F_{*}}\right] E_{t} f_{t+1}-\left[\frac{1}{1-\delta(1-\kappa)} \cdot \frac{P D V_{*}^{\kappa}}{1-P D V_{*}^{\kappa}}\right]\left(p d v_{t}^{\kappa}-\delta(1-\kappa) E_{t} p d v_{t+1}^{\kappa}\right) \\
& +\left[\frac{1}{1-\delta(1-\kappa)}\right]\left(r_{t}^{f}-E_{t} \pi_{t+1}\right) \\
& -\left[\frac{\chi \cdot \kappa}{1-\delta(1-\kappa)} \cdot \frac{1}{1-P D V_{*}^{\kappa}}\right]\left(\delta E_{t} k_{t+2}-(1+\delta) k_{t+1}+k_{t}\right),
\end{aligned}
$$

where

$$
p d v_{t}^{\kappa}=\delta(1-\kappa) E_{t} p d v_{t+1}^{\kappa}+(1-\delta(1-\kappa)) E_{t} f_{t+1}-r_{t}^{f} .
$$

This simplifies to:

$$
\begin{aligned}
E_{t} r_{t+1}^{k} & =\left[\frac{1-\frac{\delta}{\Pi_{*}}}{1-\frac{\delta}{\Pi_{*}}\left(1-\kappa\left(1-F_{*}\right)\right)} \cdot \frac{F_{*}}{1-F_{*}}\right] E_{t} f_{t+1} \\
& +\left[\frac{1}{1-\delta(1-\kappa)}\right]\left(r_{t}^{f}-E_{t} \pi_{t+1}\right)+\left[\frac{1}{1-\delta(1-\kappa)} \cdot \frac{\frac{\delta}{\Pi_{*}} \kappa F_{*}}{1-\frac{\delta}{\Pi_{*}}\left(1-\kappa\left(1-F_{*}\right)\right)}\right] r_{t}^{f} \\
& -\left[\frac{\chi \cdot \kappa}{1-\delta(1-\kappa)} \cdot \frac{1-\frac{\delta}{\Pi_{*}}(1-\kappa)}{1-\frac{\delta}{\Pi_{*}}\left(1-\kappa\left(1-F_{*}\right)\right)}\right]\left(\delta E_{t} k_{t+2}-(1+\delta) k_{t+1}+k_{t}\right)
\end{aligned}
$$




\section{C.4 Corporate Income Taxation and the Interest Rate Sensitivity of the Model's User Cost Expression}

Section 5.1 claimed that the user cost expression implied by the model is affected by changes in the real posttax interest rate and the posttax nominal rate in a manner that is quantitatively similar to what would be implied by a standard Hall-Jorgenson formula that is calibrated using the tax rate on corporate income. We now demonstrate this claim.

Using the calibrated parameter values discussed in Appendix A, it is straightforward to show that equation (36) implies that a one percentage point increase in the real posttax rate of interest raises the user cost by an amount that is 4.8 times larger than the effect of a one percentage point increase in the posttax nominal interest rate.

Now consider the Hall-Jorgenson user cost formula when corporate income is taxed at the rate $F^{c}$. In the one-good model considered here, this equals

$$
\frac{(\phi+\kappa)\left(1-F^{c} z\right)}{1-F^{c}}
$$

where $z$ denotes the present value of depreciation allowances and $\phi$ is the firm's real cost of funds.

We set $\phi$ equal to the steady-state real posttax rate of return that is implied by our model calibration. ${ }^{27}$ Over the 1970 to 1997 period, the Federal corporate income tax rate averages 41.5 percent, while the ratio of state and local corporate profits taxes to NIPA book profits averages 5.8 percent; we therefore set $F^{c}$ equal to 47.3 percent. Finally, we assume that depreciation allowances are computed using economic depreciation. Under these assumptions, we obtain that a one percentage point increase in the real posttax interest rate has an effect on the Hall-Jorgenson user cost that is 4.0 times greater than a one percentage point increase in the posttax nominal interest rate. This is similar to the relative effect that is implied by our model.

\footnotetext{
${ }^{27}$ For a debt-financed firm, $\phi$ will be approximately equal to the posttax real rate if $F^{c}$ is close to the personal income tax rate faced by the marginal investor — see Cohen, Hassett, and Hubbard (1999).
} 
Table 1: Lower Bounds for Equilibrium Determinacy

\begin{tabular}{lccccc}
\hline \hline & \multicolumn{5}{c}{ Coefficient on output gap in Taylor rule } \\
\cline { 2 - 6 } & $\gamma=0.0$ & $\gamma=0.125$ & $\gamma=0.25$ & $\gamma=0.5$ & $\gamma=1.0$ \\
\cline { 2 - 6 } & & & & & \\
A. Model without capital & & & & & \\
1. No taxes & 1.00 & 1.00 & 0.99 & 0.98 & 0.97 \\
2. With nominal taxes & 1.42 & 1.42 & 1.41 & 1.40 & 1.39 \\
3. With real taxes & 1.00 & 1.00 & 0.99 & 0.98 & 0.97 \\
B. Model with capital & & & & & \\
& & & & & \\
4. No taxes & 1.00 & 0.99 & 0.99 & 0.97 & 0.94 \\
5. With nominal taxes & 1.42 & 1.41 & 1.41 & 1.39 & 1.37 \\
& & & & & \\
\hline \hline
\end{tabular}

Note: The table gives the lower bounds for $\beta$ (the coefficient on inflation in the Taylor rule) that are required for equilibrium determinacy. See text for additional details. 
Table 2: Equilibrium Determinacy and Stability with Depreciation Allowances

\begin{tabular}{|c|c|c|}
\hline & \multicolumn{2}{|c|}{ Smallest value of $\beta$ required for: } \\
\hline & Determinacy & Stability \\
\hline \multicolumn{3}{|c|}{ A. Output-gap weight $=0.0$} \\
\hline$\rho=0.0$ & \multicolumn{2}{|c|}{ Always indeterminate } \\
\hline$\rho=0.5$ & 1.31 & 1.42 \\
\hline$\rho=0.9$ & 1.42 & 1.42 \\
\hline \multicolumn{3}{|c|}{ B. Output-gap weight $=0.125$} \\
\hline$\rho=0.0$ & \multicolumn{2}{|c|}{ Always indeterminate } \\
\hline$\rho=0.5$ & 1.50 & 1.72 \\
\hline$\rho=0.9$ & 1.72 & 1.72 \\
\hline \multicolumn{3}{|c|}{ C. Output-gap weight $=0.25$} \\
\hline$\rho=0.0$ & 1.65 & 2.02 \\
\hline$\rho=0.5$ & 1.72 & 2.02 \\
\hline$\rho=0.9$ & 2.02 & 2.02 \\
\hline \multicolumn{3}{|c|}{ D. Output-gap weight $=0.5$} \\
\hline$\rho=0.0$ & 2.10 & 2.61 \\
\hline$\rho=0.5$ & 2.17 & 2.61 \\
\hline$\rho=0.9$ & 2.56 & 2.61 \\
\hline \multicolumn{3}{|c|}{ E. Output-gap weight $=1.0$} \\
\hline$\rho=0.0$ & 3.02 & 3.79 \\
\hline$\rho=0.5$ & 3.08 & 3.79 \\
\hline$\rho=0.9$ & 3.50 & 3.79 \\
\hline
\end{tabular}

Note: The table gives the lower bounds for $\beta$ (the coefficient on inflation in the Taylor rule) that are required for determinate and stable rational expectations equilibria. See text for additional details. 